\title{
Finite element simulation of AISI 1025 and Al6061 specimen with coated and uncoated tools on turning process using deform-3D
}

\author{
KV Durga Rajesh $^{1 *}$, Abdul Munaf Shaik ${ }^{1}$, A V S Ram Prasad ${ }^{1}$, Tanya Buddi ${ }^{2}$, and F M Mwema ${ }^{3}$ \\ ${ }^{1}$ Department of Mechanical Engineering, Koneru Lakshmaiah Education Foundation, Vaddeswaram, Andhra Pradesh, India \\ ${ }^{2}$ Department of Mechanical Engineering, GRIET, Bachupally, Hyderabad, Telangana, India \\ ${ }^{3}$ Department of Mechanical Engineering, Dedan Kimathi University of Technology, Nyeri, Kenya
}

\begin{abstract}
This paper describes how to use Deform-3D software to create a turning process model that can be used to simulate the turning on AISI 1025 carbon steel and Al6061 billets in industrial and automotive applications. The Deform-3D Software is used to build a 3D Finite Element turning model. Pre-processing, Simulation, and Post-processing are all modules that can be used to simulate. Tool and workpiece information, as well as appropriate necessary parameters, were taken into account in the software's Pre Processing module. Simulation was performed at two different rotational speeds for two different materials using with and without titanium nitride coated tungsten carbide tool. After 1000 steps of simulation, results such as damage, effective strain, effective stress, total velocity, total displacement, and Temperature are reported from the Post Processing module. From results, comparative analysis will be carried out on performance characteristics at different rotational speeds. During the turning process, to accurately predict metal removal Deform 3D software is used for finite element simulation.
\end{abstract}

\section{Introduction}

Turning is a cutting technique in which a single point cutting tool, usually aided by cutting fluids, separates material from a rotating workpiece. The tool is usually mounted on a tool post, and the workpiece is kept in a chuck or other work holding unit. By extracting chips from a spinning workpiece that have been fed into a cutting tool and swept away by the work piece's movement, the tool gradually creates a surface. Turning is often used as a secondary method to modify or refine features on parts that have already been produced. As a consequence, chip disposal in turning and cutting fluid effectiveness are crucial. Steel and aluminium are most commonly used materials in manufacturing industries. In the automotive and manufacturing industries, steel and aluminium are the most widely used materials. Since AISI 1025 carbon steel is used in machinery parts and trusses, and Al6061 is used in aircrafts and heat exchangers, these materials were chosen. Deform 3D is one of the Finite Element simulation software which performs several machining operations with variable parameters as constraints. Setting simulation controls plays an important role when analyzing. Many researchers indicated the various factors like selection of material, work piece, feed, depth of cut, convection coefficient etc. which influences the performance.

Cutting forces and processes can perfectly simulated by Deform-3D Finite Element Modelling (FEM) software
[1]. Chen Zhuo et al. carried out experiments on Titanium TC4 and curved model system with standard parameters to validate the accuracy of Deform-3D. Shraddha et al. [2] worked on machining of Ti-6Al-4V to reveal the thermal distribution using this $3 \mathrm{D}$ simulation software. A model for machining this alloy has been proposed for FEM of temperature distribution. Since laboratory experiments are expensive and time consuming, metal cutting simulation is a viable option in order to obtain a better distinguishing of fabricating processes under different cutting conditions. The effect of process parameters such as cutting speed and feed with a constant depth of cut of $0.25 \mathrm{~mm}$ was evaluated using a L9 orthogonal array based on configuration of experiments on Ti-6Al-4V as workpiece material by $\mathrm{K}$. Satyanarayana et al. [3]. By using Deform-3D simulation, While machining AISI 1045 steel Tamizharasan et al. [4] attempted to minimize flank wear and performance quality characteristics were evaluated using statistical techniques for L9 orthogonal array.

Some researchers worked on different machining processes on Magnesium alloys, same has been simulated on Deform-3D. Using DEFORM 3D tools, Anirudh Muralidharan [5] investigated 6 different materials for 5 different depths of cut and different frequencies of feed. Amit Sharma et al. [6] examined and simulated the effects of variables on Ti-6Al-4V turning. Corina Constantin et al. [7] explains overview of

\footnotetext{
* Corresponding author: kanchurajesh@ $@$ kluniversity.in
} 
possibilities when using FEM. Analyzed various machining processes and projected cutting pressures, tool wear, temperatures and stresses, so that the cutting tool could be optimized. The use of the finite element method to work on metal cutting operations and chip forming has proven to be successful. Researchers, as well as computer and equipment manufacturers, may use the simulation findings to design new instruments and refine the cutting process. Orthogonal and oblique cutting operations were modelled by E. Ceretti et al. [8]. Libo $\mathrm{Wu}$ et al. [9] looked at cutting power, chip formation, chip morphology, and chip geometric parameters in relation to chip-breaking grooves in some studies. Rityuj Singh Parihar et al. [10] examined the reaction of key machining variables in ceramic tool turning on AISI H13 material. Interfacial temperature affects tool wear and can also influence the work piece and tool parameters in machining [11].

R. Rajesh et al. [12] has considered, titanium and aluminium alloys with coatings to study the tool wear characteristics. The base metal of the tool bit is tungsten carbide, which has been treated with three different materials: $\mathrm{Ti}, \mathrm{Al}_{2} \mathrm{O}_{3}$, and TiCN. The turning mechanism of alloy steel AISI 4340 using a Nano $\mathrm{Al}_{2} \mathrm{O}_{3}$ tool is investigated in $3 \mathrm{D}$ numerical models at various turning speeds were studied by Hong-jun $\mathrm{Hu} \& W e i-j i u$ Huang [13] to forecast the evolutions of tool turning powers, and wear rate in tools. L.R. Kilmetova \& and P.V. Sletnev [14] compared the simulation of aluminium alloys with experimental process and analyzes the temperature distribution with respect to cutting speed. K. V. Durga Rajesh et al. [15] was performed simulation process on Deform-3D software for forging operation which was considered as a basic to work on Deform-3D software for the present work.

Steel and Aluminium work pieces are taken for simulation under standard working parameters with change in rotational speeds. To obtain better results from finite element analysis, the turning set-up geometry, Tool setup data and workpiece setup details have been carefully described in this study. With and without tool coating, the effects of damage, effective stress, effective strain, total displacement, total velocity, and temperature were investigated.

\section{Methodology}

The Design Environment for Forming (DEFORM $3 \mathrm{D}$ V6.1) software is used to simulate the turning process model in this paper. In this methodology, process to run simulation on turning process using DEFORM 3D Software is explained in detail. In Pre processor stage after opening the software, first project and operation names with unit system details are to be entered. In this work, System International (SI) has been selected. Machining type like turning, milling, drilling, boring need to be selected next depending upon type of operation performed on software, for this work turning operation has been identified. The following process setup details shown in table 2.1., are considered to perform simulation of turning operation.
Table 2.1. Process setup parameters for simulation

\begin{tabular}{|c|c|}
\hline Parameter & Value \\
\hline Rotational Speed & $1000 \mathrm{rpm} \& 2000 \mathrm{rpm}$ \\
\hline Workpiece Diameter (D) & $50 \mathrm{~mm}$ \\
\hline Depth of cut (d) & $0.5 \mathrm{~mm}$ \\
\hline Feed rate (f) & $0.3 \mathrm{~mm} / \mathrm{rev}$ \\
\hline Environment Temperature & $300 \mathrm{C}$ \\
\hline Convection coefficient & $0.02 \mathrm{~N} / \mathrm{Sec} / \mathrm{mm} / \mathrm{C}$ \\
\hline Shear friction factor & 0.6 \\
\hline Heat Transfer coefficient & $45 \mathrm{~N} / \mathrm{Sec} / \mathrm{mm} / \mathrm{C}$ \\
\hline
\end{tabular}

After considering the above mentioned parameters, tool setup details are to be entered. Where one can define new tool or existing tool from library. Here tool with and without coating options has been selected from existing library. Uncoated tungsten carbide tool details and parameters considered are mentioned in Table 2.2. Coated tungsten carbide tool with titanium nitride details and parameters considered are mentioned in Table 2.3. Tool holder setup of DTGNL was selected to perform ope.

Table 2.2. Uncoated tool details

\begin{tabular}{|c|c|}
\hline \multicolumn{2}{|c|}{ Tool type: TNMA332 (without coating) } \\
\hline IC & $9.53 \mathrm{~mm}$ \\
\hline $\mathrm{B}$ & $13.494 \mathrm{~mm}$ \\
\hline $\mathrm{T}$ & $4.76 \mathrm{~mm}$ \\
\hline $\mathrm{H}$ & $3.81 \mathrm{~mm}$ \\
\hline $\mathrm{R}$ & $0.8 \mathrm{~mm}$ \\
\hline
\end{tabular}

Table 2.3. Coated tool details

\begin{tabular}{|c|c|}
\hline \multicolumn{2}{|c|}{$\begin{array}{c}\text { Tool type: TNMA332_KC90 (with titanium nitride } \\
\text { coating) }\end{array}$} \\
\hline $\mathrm{IC}$ & $9.53 \mathrm{~mm}$ \\
\hline $\mathrm{B}$ & $13.494 \mathrm{~mm}$ \\
\hline $\mathrm{T}$ & $4.76 \mathrm{~mm}$ \\
\hline $\mathrm{H}$ & $3.81 \mathrm{~mm}$ \\
\hline $\mathrm{R}$ & $0.8 \mathrm{~mm}$ \\
\hline Coated layer & 1 \\
\hline Coated thickness & $1 \mathrm{~mm}$ \\
\hline Coated material & TiN \\
\hline
\end{tabular}

After considering all tool details, tool need to be meshed. With meshing the entire tool portion will be divided into finite number of nodes, elements and all required boundary conditions are constrained to perform simulation in later stage. Under Tool mesh generation option, size ratio of 4 and relative mesh size option was selected, where minimum half of the maximum elements to be entered to get better and quality mesh. Fig. 2.1. shows a solid mesh with 29804 components and 6888 nodes for simulation for a tungsten carbide uncoated tool. 


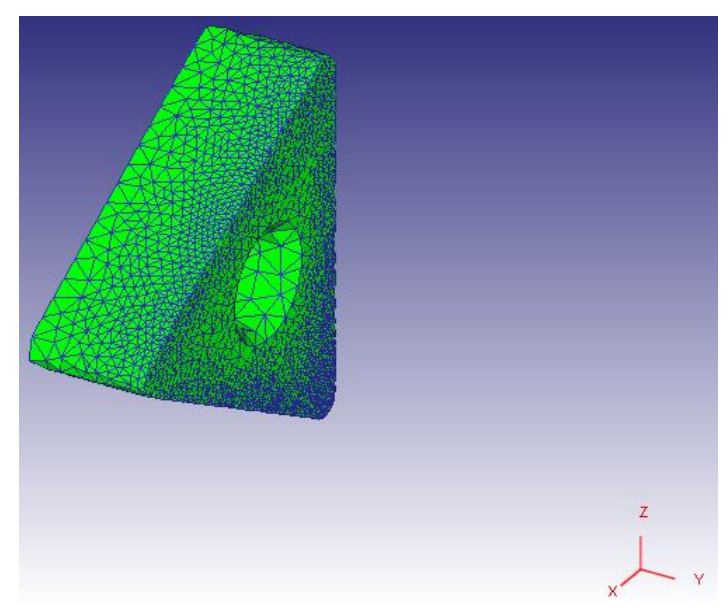

Fig. 2.1. Tool meshed model

After considering all tool required data, now workpiece related data need to be selected. To perform simulation on turning process both tool and workpiece plays key role. Workpiece type of plastic was opted with ambient temperature condition of $30^{\circ} \mathrm{C}$. Default workpiece shape was considered, which was available in the library of software to perform analysis. Like tool, workpiece also need to be meshed and constrained before go to simulation. With relative mesh size method, steel workpiece was meshed with 3821 elements and 967 nodes for simulation shown in Fig. 2.2.

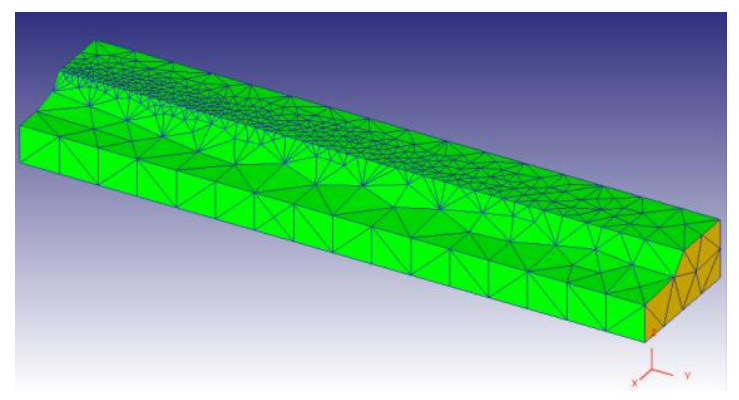

Fig. 2.2. Workpiece meshed model

Selection of workpiece material is an important task to perform simulation. In this work, two different materials like AISI 1025 carbon steel and Al6061 were considered for analysis. To run simulation, Simulation controls need to be selected and the same was shown in Table 2.4. Database need to be checked and generated before run the simulation. Then simulation stage will be started for 1000 steps. The process started at step- 1 is selected for reference and shown in Fig. 2.3. After completion of 1000 steps simulation will be completed and results will be taken from post processor stage.

Table 2.4. Process setup parameters for simulation

\begin{tabular}{|c|c|}
\hline Parameter & Value \\
\hline Number of simulation steps & 1000 \\
\hline Step increment to save & 25 \\
\hline Arc length to cut & $19.5 \mathrm{~mm}$ \\
\hline
\end{tabular}

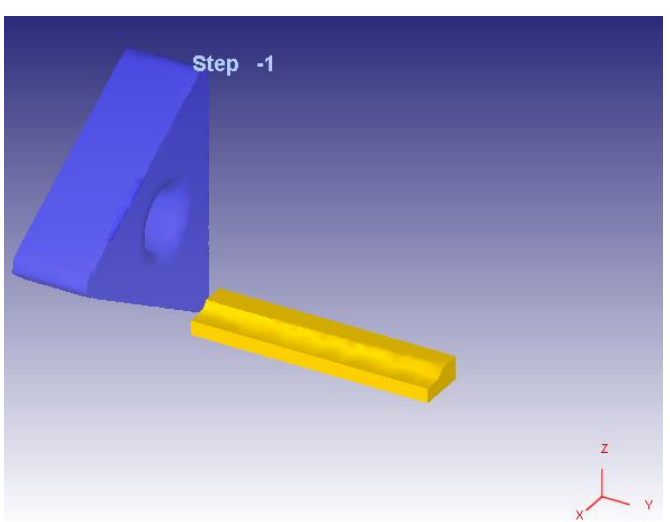

Fig. 2.3. Simulation at step-1

In the present work, Simulation can be performed at two different rotational speeds like $1000 \mathrm{rpm}$ and 2000 rpm, under optimal tool geometry. Two work piece materials AISI 1025 carbon steel and Al6061 were considered for the simulation process with titanium nitride coated and uncoated tungsten carbide tool. 8 datasets were considered to perform simulation. Data sets details are mentioned below in Table 2.5.

Table 2.5. Description of 8 datasets

\begin{tabular}{|c|c|}
\hline $\begin{array}{c}\text { Data Set } \\
\text { No. }\end{array}$ & Description \\
\hline 1 & $\begin{array}{c}\text { Simulation on AISI 1025 carbon steel workpiece } \\
\text { with uncoated tungsten carbide tool at 1000 rpm } \\
\text { rotational speed }\end{array}$ \\
\hline 2 & $\begin{array}{c}\text { Simulation on Al6061 workpiece with uncoated } \\
\text { tungsten carbide tool at 1000 rpm rotational } \\
\text { speed }\end{array}$ \\
\hline 3 & $\begin{array}{c}\text { Simulation on AISI 1025 carbon steel workpiece } \\
\text { with titanium nitride coated tungsten carbide tool } \\
\text { at 1000 rpm rotational speed }\end{array}$ \\
\hline 4 & $\begin{array}{c}\text { Simulation on Al6061 workpiece with titanium } \\
\text { nitride coated tungsten carbide tool at 1000 rpm } \\
\text { rotational speed }\end{array}$ \\
\hline 5 & $\begin{array}{c}\text { Simulation on AISI 1025 carbon steel workpiece } \\
\text { with uncoated tungsten carbide tool at 2000 rpm } \\
\text { rotational speed }\end{array}$ \\
\hline 6 & $\begin{array}{c}\text { Simulation on Al6061 workpiece with uncoated } \\
\text { tungsten carbide tool at 2000 rpm rotational } \\
\text { speed }\end{array}$ \\
\hline 8 & $\begin{array}{c}\text { Simulation on AISI 1025 carbon steel workpiece } \\
\text { with titanium nitride coated tungsten carbide tool } \\
\text { at 2000 rpm rotational speed }\end{array}$ \\
\hline & $\begin{array}{c}\text { Simulation on Al6061 workpiece with titanium } \\
\text { nitride coated tungsten carbide tool at 2000 rpm } \\
\text { rotational speed }\end{array}$ \\
\hline
\end{tabular}

After successful completion of the simulation process on 8 datasets, the results obtained are discussed in next section.

\section{Results and Discussion}

Simulation analysis is carried out with the defined optimal tool geometry, and performance characteristics like damage, total displacement, effective strain, effective 
stress, temperature, and total velocity obtained for dataset-1 are shown below.

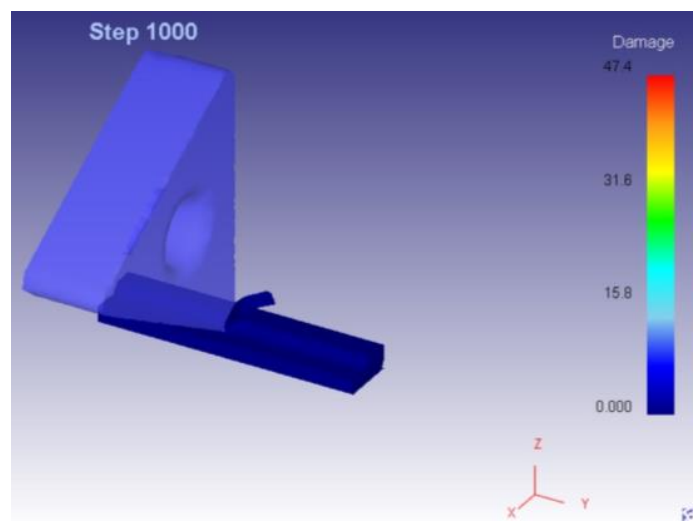

Fig. 3.1. Damage for Dataset-1

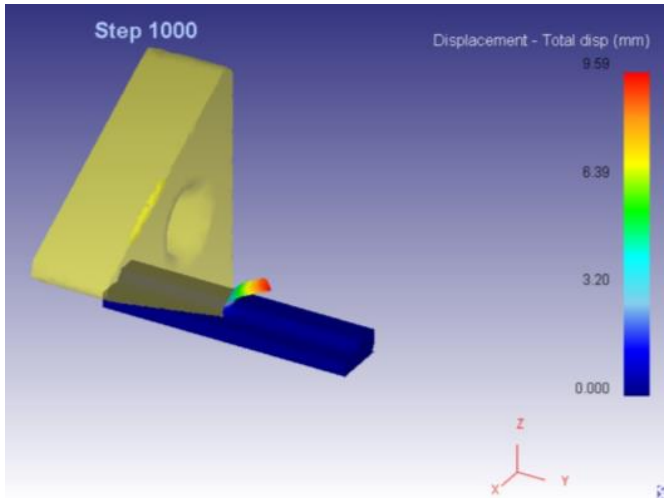

Fig. 3.2. Displacement for Dataset-1

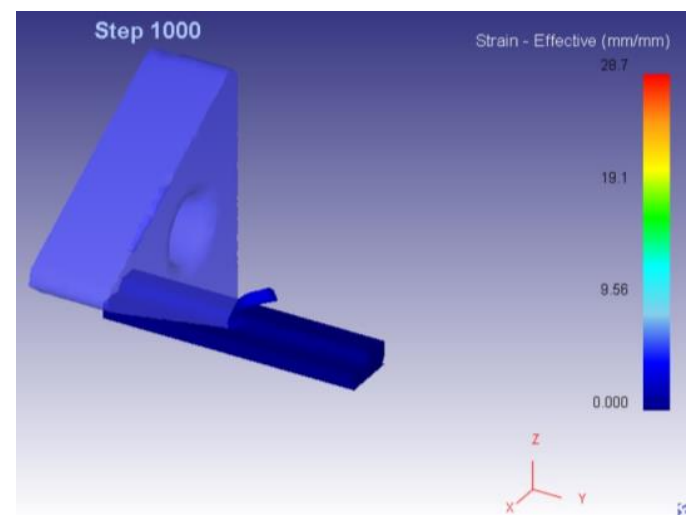

Fig. 3.3. Strain Effective for Dataset-1

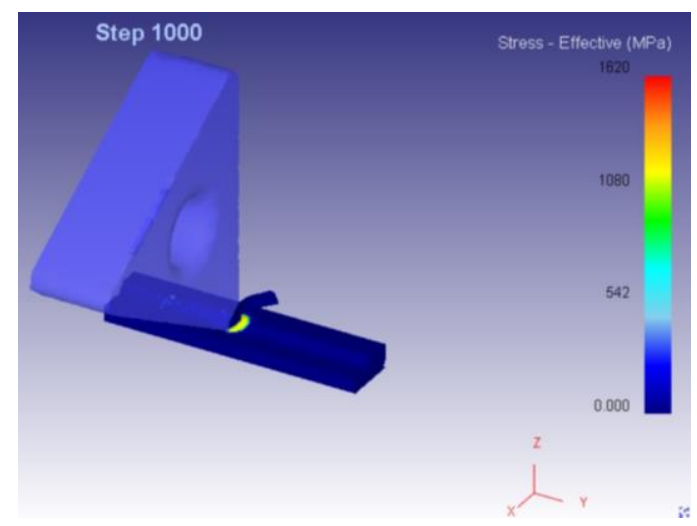

Fig. 3.4. Stress Effective for Dataset-1

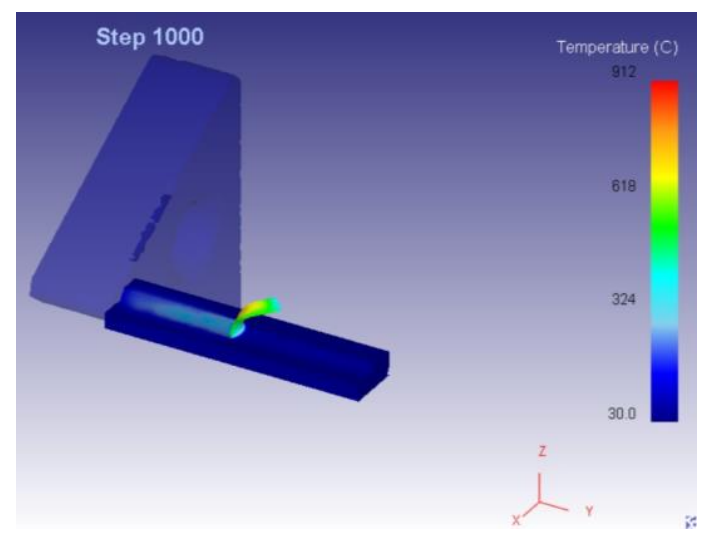

Fig. 3.5. Temperature for Dataset-1

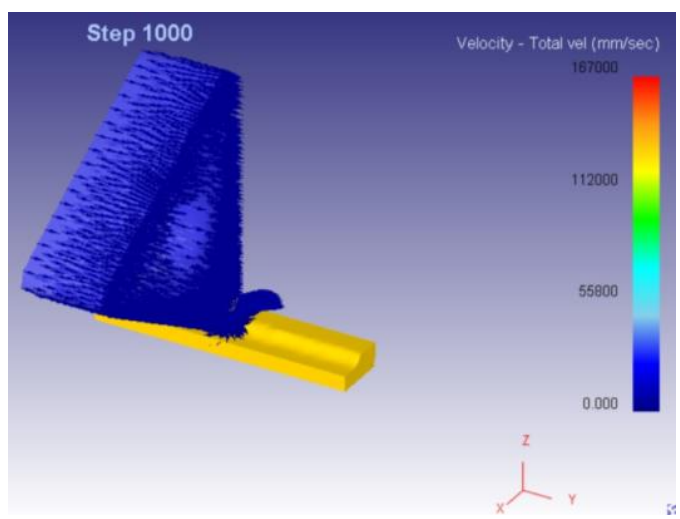

Fig. 3.6. Velocity for Dataset-1

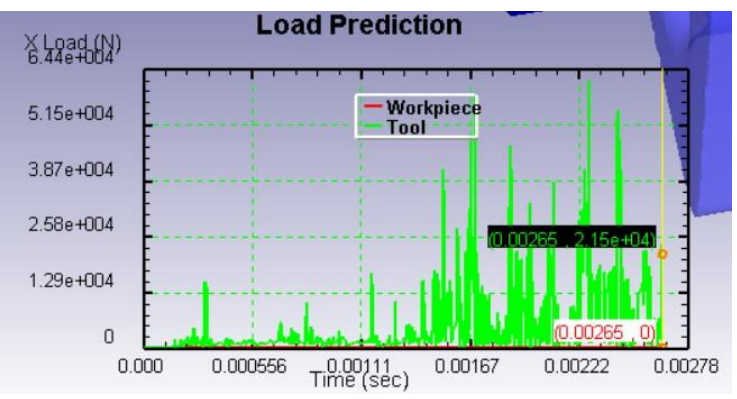

Fig. 3.7. Optimal load prediction in X-Load (N) for Dataset-1

From the Fig. 3.1. to 3.6., it was observed that the maximum damage, total displacement, effective strain, effective stress, temperature and total velocity are 47.4, $9.59 \mathrm{~mm}, 28.7 \mathrm{~mm} / \mathrm{mm}, 1620 \mathrm{Mpa}, 912{ }^{\circ} \mathrm{C}$ and 167000 $\mathrm{mm} / \mathrm{sec}$ respectively. From the figure 3.7 , the X-Load is maximum at $0.00222 \mathrm{sec}$. Similarly from the figure 3.8 , the Y-Load is maximum at $0.00122 \mathrm{sec}$ and from the figure 3.9, the Z-Load is maximum at $0.00174 \mathrm{sec}$. Same process is repeated for another 7 datasets. The results obtained from 7 datasets are shown in table 3.1 along with dataset-1 results.

Table 3.1. Performance characteristics of 8 datasets

\begin{tabular}{|c|c|c|c|c|c|c|}
\hline $\begin{array}{c}\text { Data } \\
\text { Set }\end{array}$ & $\begin{array}{c}\text { Dam } \\
\text { age }\end{array}$ & $\begin{array}{c}\text { Displa } \\
\text { cement } \\
(\mathbf{m m})\end{array}$ & $\begin{array}{c}\text { Effecti } \\
\mathbf{v e} \\
\text { Strain } \\
(\mathbf{m m} / \\
\mathbf{m m})\end{array}$ & $\begin{array}{c}\text { Effecti } \\
\mathbf{v e} \\
\text { Stress } \\
\mathbf{( M ~ p a )}\end{array}$ & $\begin{array}{c}\text { Tempe } \\
\text { rature } \\
\left({ }^{\mathbf{0}} \mathbf{C}\right)\end{array}$ & $\begin{array}{c}\text { Velocit } \\
\mathbf{y} \\
(\mathbf{m m} / \mathbf{s} \\
\mathbf{e c})\end{array}$ \\
\hline $\mathbf{1}$ & 61.3 & 8.56 & 25.6 & 1310 & 1410 & 167000 \\
\hline $\mathbf{2}$ & 53.7 & 8.46 & 44.3 & 1220 & 368 & 8810 \\
\hline
\end{tabular}




\begin{tabular}{|c|c|c|c|c|c|c|}
$\mathbf{3}$ & 47.4 & 9.59 & 28.7 & 1620 & 912 & 167000 \\
\hline $\mathbf{4}$ & 83.7 & 8.21 & 29.5 & 1050 & 359 & 7520 \\
\hline $\mathbf{5}$ & 73.2 & 8.87 & 28.6 & 1420 & 1687 & 214250 \\
\hline $\mathbf{6}$ & 39 & 8.06 & 26.8 & 1430 & 417 & 29700 \\
\hline $\mathbf{7}$ & 54.4 & 8.94 & 29.8 & 1590 & 878 & 223205 \\
\hline $\mathbf{8}$ & 15.1 & 8.09 & 42.2 & 1890 & 467 & 47600 \\
\hline
\end{tabular}

From the above Table 3.1, the following points were observed.

- At 1000 rpm, except effective strain all the remaining performance characteritics are more for AISI 1025 carbon steel than Al6061 with uncoated tungsten carbide tool.

- At $1000 \mathrm{rpm}$, using titanium nitride coated tungsten carbide tool the damage and effective strain values are less for AISI 1025 carbon steel than Al6061.

- At $2000 \mathrm{rpm}$, for Al6061 the value of damage is more while using the uncoated tungsten carbide tool.

- For Al6061, at $2000 \mathrm{rpm}$ all performance characteritics except damage are low for uncoated tool than titanium nitride coated tungsten carbide tool.

- For AISI 1025 Carbon steel, at $1000 \mathrm{rpm}$ the value of damage and temperature are more for uncoated tool than titanium nitride coated tungsten carbide tool.

At $1000 \mathrm{rpm}$, while machining with AISI 1025 carbon steel using uncoated tool displacement, temperature and velocity are more than machining Al6061 with coated tool.

\section{Conclusion}

After performing turning operation at two different rotational speeds 1000 and $2000 \mathrm{rpm}$, from both coated and uncoated tungsten carbide tool it was observed that, with increase in rotational speed, damage rate is reduced and displacement remains unchanged. With decrease in rotational speed, effective stress, total velocity and temperature were decreased. With titanium nitride coated tool the effective stress, effective strain, velocity, and temperature were reduced than uncoated tool for the experimental datasets considered. So, it was concluded that the coated tools are preferable to produce optimal results in most cases.

\section{References}

1. C. Zhuo, Q.L. fang and Y.L. juan., Cutting Force Simulation of Titanium based on DEFORM-3D. Proceedings of the 3rd International Conference on Material Mechanical and Manufacturing Engineering, 1846 (2015).

2. S.S. Adewar, Int. Res. J Engg., 6, (2019)

3. K. Satyanarayana, A.V. Gopal, P.B. Babu., Proceedings of the ASME 2013 International Mechanical Engineering Congress and Exposition, San Diego, California, USA, (2013).

4. T. Tamizharasan, N.S. Kumar., Int. J Simul. Mod., 11, 65 (2012).
5. A. Muralidharan, Project report (SURGE 2015), IIT Kanpur.

6. A. Sharma, C.S. Kalra, R. Rohit., Int. J Engg. Res. Tech., 2, (2013).

7. C. Constantin, S.M. Croitoru, G. Constantin, C.F. Bisu., Adv. Vis., Imag. Sim., 41 (2010).

8. E. Ceretti, C. Lazzaroni, L. Menegardo, T. Altan, J Mat. Proc. Tech., 98, 99 (2000).

9. L. Wu., Int. J Adv. Mfg. Tech., 108, 1331.

10. R.S. Parihar, R.K. Sahu, G. Srinivasu., Mat. Tod. Proc., 4, 8432, (2017).

11. Y.R. Bhoyar, P.D. Kamble., Int. J Res Engg. Tech., 2, (2013).

12. R. Rajesh, J.L. Mercy, S.R. kumar, A. Singh., ARPN J Engg. App. Sci., 12, (2017).

13. H.J. Hu, W. J. Huang., Int. J Adv. Mfg. Tech., 67, 907 (2013).

14. L.R. Kilmetova, P.V. Sletnev., J Engg. Sci. Tech Rev., 7, 29 (2014).

15. K.V.D. Rajesh, T. Buddi, H. Mishra., Adv. Mat. Proc. Tech., (2021). (accepted and to be Published). 